\title{
The Kilopower Reactor Using Stirling TechnologY (KRUSTY) Nuclear Ground Test Results and Lessons Learned
}

\author{
Marc Gibson, ${ }^{1}$ David Poston ${ }^{2}$, Patrick McClure ${ }^{2}$, Thomas Godfroy ${ }^{3}$, Maxwell Briggs ${ }^{1}$, James Sanzi ${ }^{3}$ \\ ${ }^{\prime}$ NASA Glenn Research Center, Cleveland, OH, 44135, U.S. \\ ${ }^{2}$ Los Alamos National Lab, Los Alamos, NM, 87545 \\ ${ }^{3}$ Vantage Partners LLC, Brookpark, $\mathrm{OH}, 44142$
}

The Kilopower nuclear ground testing nicknamed KRUSTY (Kilopower Reactor Using Stirling TechnologY) was completed at the Nevada Nuclear Security Site (NNSS) on March 21, 2018. This full scale nuclear demonstration verified the Kilopower reactor neutronics during startup, steady state, and transient operations in a space simulated environment. This was the first space reactor test completed for fission power systems in over 50 years and marked a turning point in NASA's nuclear program. The completed reactor power system design incorporated flight prototypic materials and full-scale components in an effort to study the reactor dynamics at full power and significantly reduce follow on risk of a future flight demonstration. This design provided a unique opportunity for the power system to simulate several nominal and off-nominal mission scenarios that allowed the designers to verify that the reactor dynamics could tolerate many worst case conditions regarding reactor stability and control. The dynamic changes imposed on the reactor validated the ability of the reactor to load follow the power conversion system and passively control the fuel temperature and overall system stability. With successful completion of the KRUSTY experiment, the NASA/DOE team will evaluate the lessons learned throughout the project and apply them towards a flight demonstration of a Kilopower reactor.

\section{Nomenclature}

$\begin{array}{ll}D O E & =\text { Department of Energy } \\ H E U & =\text { Highly Enriched Uranium } \\ N A S A & =\text { National Aeronautics and Space Administration } \\ N N S S & =\text { Nevada National Security Site } \\ N N S A & =\text { National Nuclear Security Administration } \\ \mathrm{KRUSTY} & \text { Kilopower Reactor Using Stirling TechnologY } \\ \mathrm{kW}_{\mathrm{t}} & =\text { Kilowatts Thermal } \\ k W_{e} & =\text { Kilowatts Electric } \\ D U F F & =\text { Demonstration Using Flattop Fissions } \\ M L I & =\text { Multi-Layer Insulation } \\ S L P M & =\text { Standard Liters Per Minute } \\ R A P & =\text { Radiation Alarm Protection } \\ T_{0} & =\text { Reactor starting Time of } 0.0 \text { hours } \\ \mathrm{DAC} & =\text { Data Acquisition and Control } \\ \mathrm{DAF} & =\text { Device Assembly Facility }\end{array}$

\section{Introduction}

The Kilopower project was officially started in 2015 to develop a fission reactor that could be scaled from 1 to $10 \mathrm{~kW}_{\mathrm{e}}$ and be applicable for both science and human exploration [3]. Completing the proof of concept DUFF nuclear test in 2012 gave NASA confidence that performing nuclear ground testing could be done affordably when partnering with the NNSA and using their existing facilities [4][5]. For 3-1/2 years the Kilopower team successfully developed a power system that could be qualified within NASA facilities using electrical heat and then be transported to DOE 
facilities and tested using nuclear fuel. The main goal of Kilopower was to execute a full power nuclear ground test at the DAF facility within a three year time window. This test took on the name KRUSTY and had three main objectives:

Objective 1: Operate the reactor at steady state with a thermal power output of $4 \mathrm{~kW}_{\mathrm{t}}$ at a temperature of $800^{\circ} \mathrm{C}$

Objective 2: Verify the stability and load following characteristics of the reactor during nominal and off-nominal conditions

Objective 3: Benchmark the nuclear codes and material cross sections using the test data

\section{Hardware Overview}

The hardware used for the KRUSTY experiment can be broken down into three basic categories: Kilopower nuclear power system, Comet criticality vertical assembly machine, and facility support equipment. The Kilopower nuclear power system flight concept and KRUSTY test hardware can be seen in figure 1. The KRUSTY test hardware was specifically designed to be as flight prototypic as possible to reduce the risk of a flight system by validating the performance of the full scale system and components. Therefore, the core, reflectors, heat pipes, Stirling simulators and shield structure were all full scale components related to the $1 \mathrm{~kW}_{\mathrm{e}}$ Kilopower system.

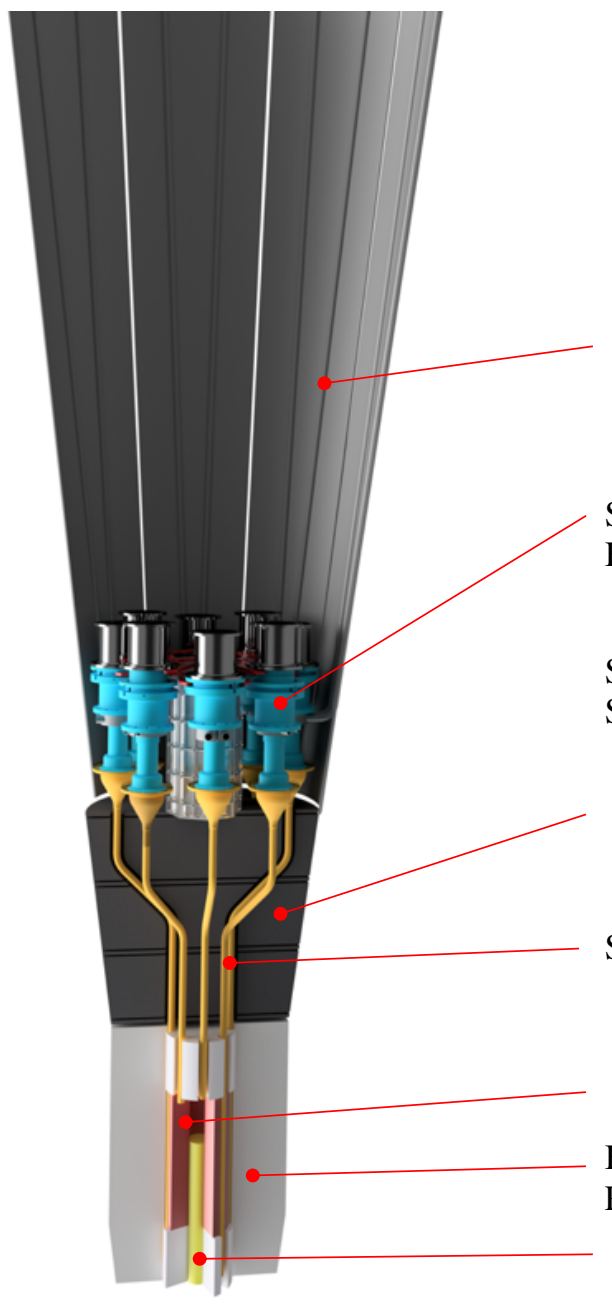

Kilopower $1 \mathrm{~kW}$ e Flight Concept
Radiator
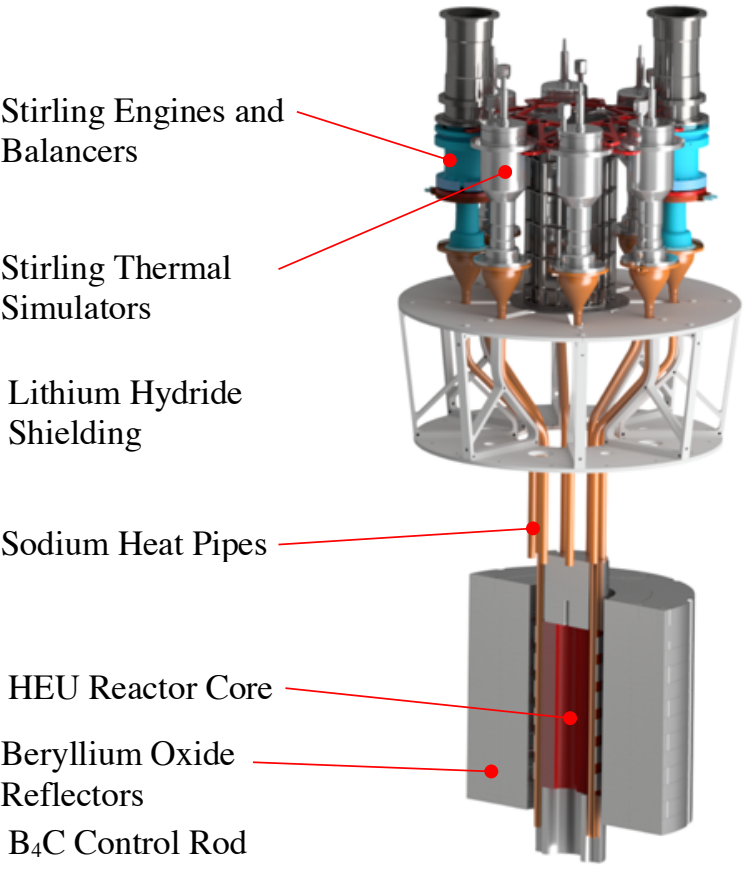

Kilopower KRUSTY Test Hardware

Fig. 1 Kilopower 1 kW nuclear power system flight concept comparison with KRUSTY nuclear test hardware 


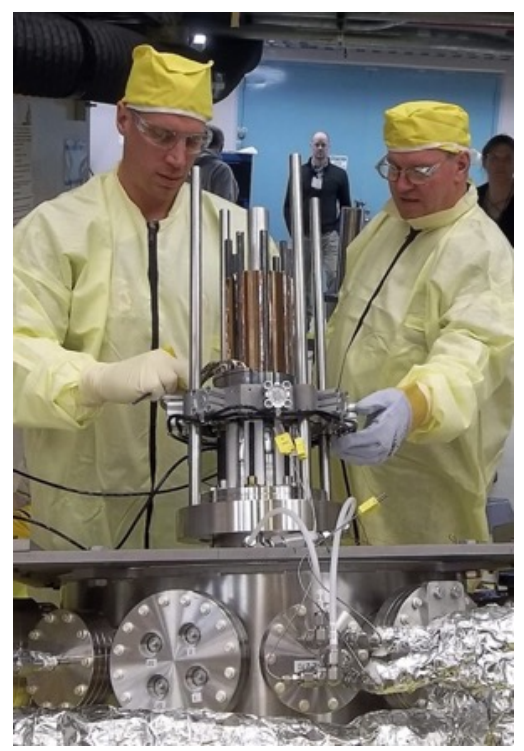

Fig. 2 Installing interference band clamps around HEU core and heat pipes inside DAF test area

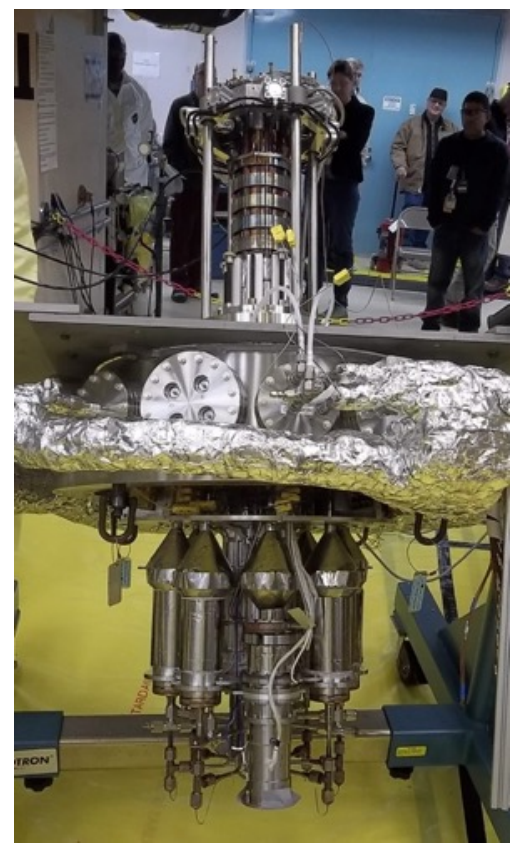

Fig. 3 KRUSTY test hardware assembled inside vacuum chamber service collar and positioned upside down with Stirling engines and simulators (lower) connected to the HEU core (upper) via the sodium heat pipes
The reactor core is made up of three sections of HEU alloyed with molybdenum to provide the steady state power of approximately $4 \mathrm{~kW}_{\mathrm{t}}$ at $800^{\circ}$ C. Each section of the core was individually made for reasons associated with criticality safety limits during the casting and machining processes. The inner diameter of the core is meant to house a boron carbide control rod that, in a flight system, is used to start, stop, and set the temperature of the reactor. The outside diameter of the core has 8 grooves cut into it where the heat pipes are secured using an interference ring clamp. Several layers of MLI are wrapped around the core to insulate the core from the structural can used to house the fueled assembly.

Figure 2 illustrates the reactor fueling process. The HEU core sections are assembled on top of each other and in between the heat pipes. Interface material is placed in between the heat pipes and uranium core to allow better thermal contact and provide a diffusion barrier. After the core sections are in place, the interference ring clamps are heated to approximately $800^{\circ} \mathrm{C}$ to allow them to clear the heat pipes as they are positioned at the appropriate locations. Once in place, the ring heater is turned off and the rings are allowed to cool, creating an interference fit around the heat pipe evaporators. This design provides several thousand pounds of clamping force and ensures good thermal contact between the heat pipes and core grooves during operation. The tooling and procedures were designed and demonstrated to be portable for use at the launch site during spacecraft assembly.

The beryllium oxide material used as the neutron reflectors was Materion Corporation's Thermalox ${ }^{\circledR} 995$. The reflectors consisted of the axial reflectors (white) which were placed above and below the core (figures 2,3) inside the vacuum vessel and the radial reflectors which were designed to be stacked around the platen centering ring as shown in figures 4 and 5. The radial reflectors incorporated several thicknesses ranging from 0.125 to 1.0 inches. The thinner sections were needed to incrementally add neutronic worth to the assembly without going over existing excess reactivity limits defined in the safety basis. During nuclear operations, the centering ring and radial reflectors would be moved up and around the core using the Comet machines moveable platen to start and stop the reactor (figure 4).

The heat pipes were made from Haynes ${ }^{\circledR} 230$ material and used sodium as the working fluid. The heat pipes were specifically designed so that the condenser could mate up with the Stirling engine heater head and be bolted using split ring clamps. The heat pipes start operating at around $400^{\circ} \mathrm{C}$ but don't move any appreciable amounts of heat until around $600^{\circ} \mathrm{C}$. At $800^{\circ} \mathrm{C}$ the heat pipes are fully operational and capable of carrying more than twice the amount of thermal energy needed to operate the Stirling engines. The heat pipes also incorporated two 45 degree bends that allow a larger assembly diameter for the engine array and provide stress relief during thermal expansion of the assembly. The eight heat pipes used for the testing were identical for both the Stirling engines and Stirling thermal simulators and performed similarly during all the testing.

The power conversion system was designed for a minimum of 8 independent $125 \mathrm{~W}$ Stirling engines that use active balancers for vibration control. The two Sunpower Inc. $80 \mathrm{~W}$ Stirling convertors used for the KRUSTY experiment were slightly smaller than the required $125 \mathrm{~W}$ needed for a $1 \mathrm{~kW}_{\mathrm{e}}$ Kilopower system but were used due to budget and schedule constraints. The $80 \mathrm{~W}$ engines were originally designed for use in a radioisotope generator and had to be modified slightly to be mounted in the 8 engine array, but they were capable of accepting an $800^{\circ} \mathrm{C}$ heat source. The balancers were also designed and built by Sunpower 


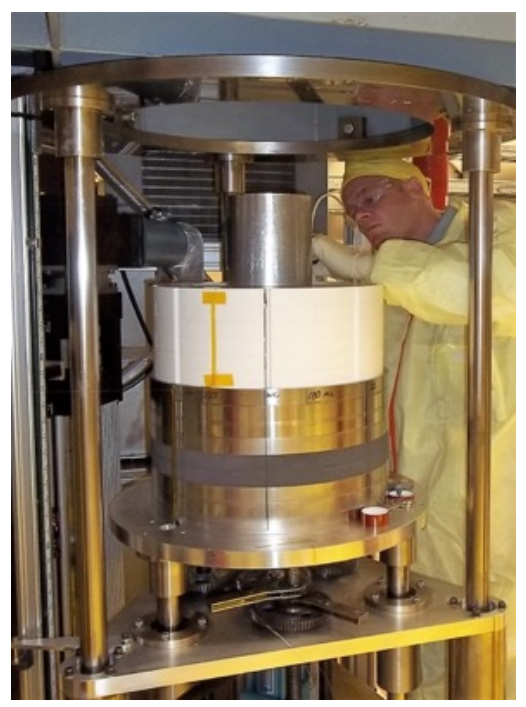

Fig. 4 Beryllium oxide radial reflectors (white) installed around centering ring and on Comet platen

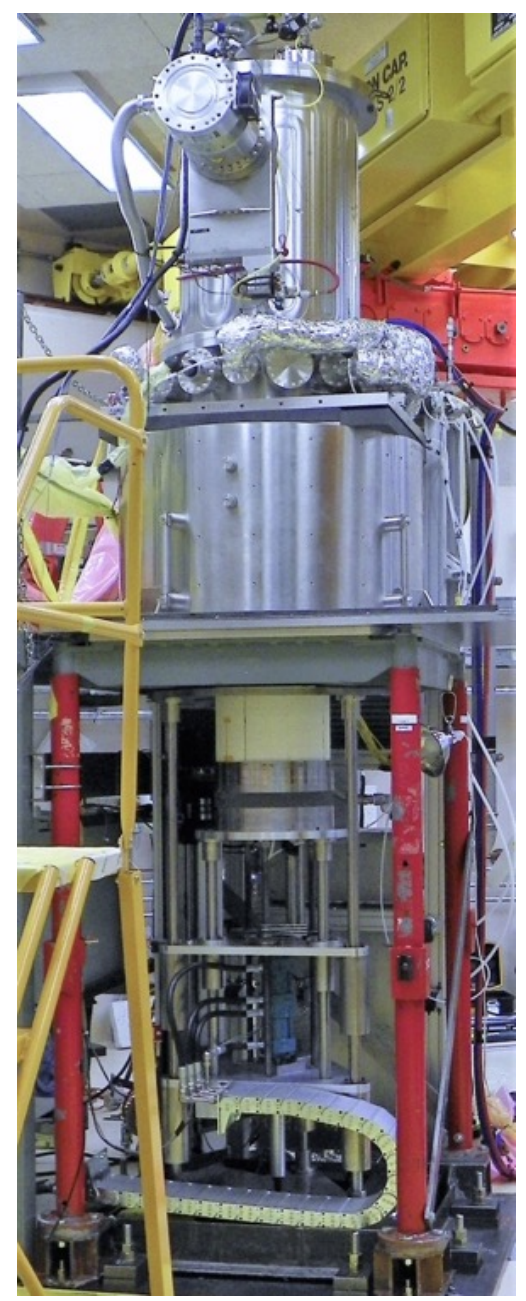

Fig. 5 Completed KRUSTY experiment setup with Comet machine, facility shielding, and vacuum system with enclosed power system and core
Inc. specifically for the Kilopower reactor test and provided active balancing for the engines during operation. Each controller independently operates one engine and balancer.

With only two Stirling convertors available, the remaining six engine locations were occupied with Stirling thermal simulators. The simulators were designed to mimic the engine thermal draw from the system by controlling the amount of gas flowing through its hot end heat exchanger. In order to keep the test a full scale thermal model, the six Stirling simulators would need to draw more heat from the core to make up for the lower power engines. During qualification testing, the simulators were able to draw a maximum of $600 \mathrm{~W}_{\mathrm{t}}$ from the heat pipe condensers. Each simulator was supplied nitrogen by a mass flow meter that provided 0-100 SLPM and was controlled by the DAC system. Thermocouples were placed in the gas stream at the inlet and exit of the simulator to provide the temperature information needed to calculate the thermal power using the mass flow and specific heat of the gas. The simulators could be controlled using a constant flow or power setting or set to actively match the thermal draw of the real Stirling engines. These Stirling simulators provided greater flexibility and control of the thermal load placed on the reactor which allowed several transient operations to be completed in the short test time.

Figure 5 shows the entire KRUSTY test setup. The Comet criticality machine on the bottom of the assembly supports all the test hardware and precisely controls the platen movement. The radial reflectors are assembled on the platen above several layers of shielding (figures 4,5) and are aligned with the core can assembly so that they can translate vertically up inside the shield and around the core. The large facility shield is seen sitting on top of Comet and its main purpose is to shield the room during the 28 hour test and support the vacuum chamber sitting on top of it. The vacuum chamber houses the power system and provides the simulated space environment for the power system and HEU core. Figure 3 shows the power system rotated upside down during the fueling operation with the Stirling engines and Stirling thermal simulators pointing down towards the ground. The vacuum chamber service collar can be used as a guide for envisioning how the power system and core are positioned inside the facility shield and vacuum chamber. It is important to note that most of the system as seen from the outside is the facility support and criticality machine hardware which would not be part of a flight system. The only flight relevant pieces are items illustrated in figure 1 .

\section{KRUSTY Results and Discussion}

The Kilopower reactor was started at approximately 9:00 am on March 20,2018 and operated for 28 continuous hours. The 28 hour time limit was a test constraint placed on the experiment to bound the total fissions produced during the experiment and the overall activation levels of the core, reactor components, and facility. This fission limit would ultimately determine the residual dose levels in the test area and the amount of elapsed time before the radiation workers could reenter the building to resume work. All the test objectives as stated previously were completed successfully through several steady state and transient operations. The reactor dynamics were very stable throughout the experiment and verified the resilience of the passive controls that do not require human or computer interaction to control the reactor after startup. Although there were several scenarios completed throughout the 28 hours of operation, only the most 
important cases will be discussed in this paper to highlight the capabilities of the reactor.

\section{A. KRUSTY Test Results Overview}

Figure 6 shows the full 28 hour test that incorporated several mission scenarios, both nominal and off-nominal. The highlights are detailed in the following paragraphs but the overview graph shows the stability of the core during the severe operating conditions. The linear RAP reading in blue is one of three neutron counters in the test cell and can be used as a scaled comparison to the reactor's thermal power. The amperage reading from the detectors are used instead of thermal power because the exact engineering calibration between amperage and watts is test specific and not easily obtained through normal calibration procedures. Although the amperage measurement is not useful to the reader, the near instant response time of the detectors gives an appreciable understanding of the thermal power being generated from the uranium core and how the core quickly responds to the system dynamics. In this graph, the green dotted boxes represent times when the platen is being moved to either startup, shutdown, or control the temperature setpoint of the reactor. For the rest of the time, the reactor is being tested for its ability to passively load follow the power conversion system during normal operations or as a response to a simulated flight system failure. During these extreme duty operations, the core temperature varied less than $4 \%$ off its nominal operating setpoint of $800^{\circ} \mathrm{C}$ during thermal load variations of over $175 \%$. This ability of the reactor to passively control itself to a near constant temperature over large power loading and fluctuations is a significant advantage for missions requiring higher power levels and ranges. As the kilopower design evolves from the flight prototypic KRUSTY hardware it is reasonable to assume that the excess reactivity needed will not change much and that future full power nuclear testing of this design will not be needed.

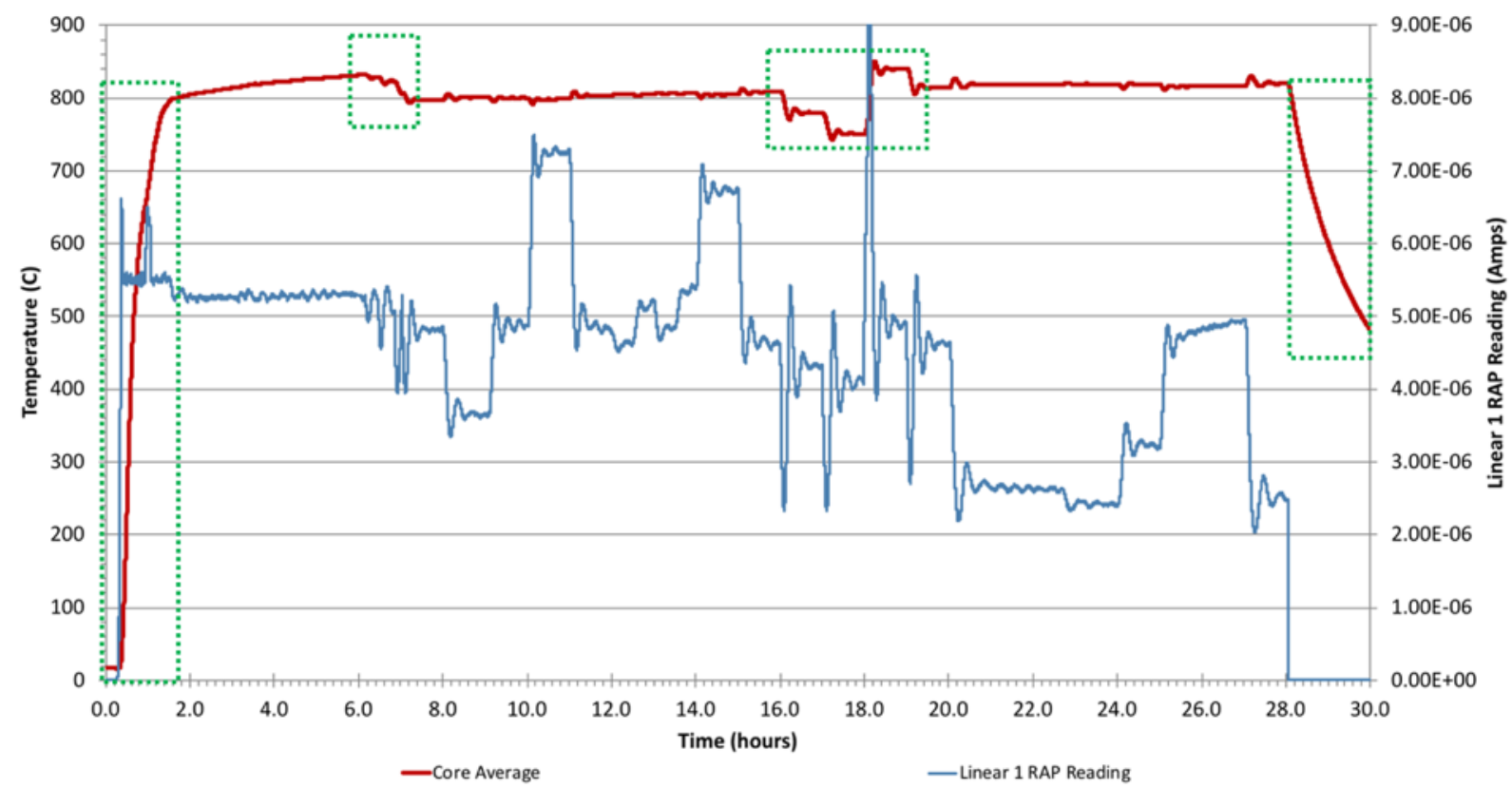

Fig. 6 KRUSTY $28 \mathrm{hr}$. test overview showing average core temperatures and neutron counter reading

\section{B. Reactor Startup}

The startup of the reactor began with a $\$ 0.15$ insertion by moving the radial reflectors up to $-17.0 \mathrm{~mm}$. Figure 7 shows the platen movement controlled through the Comet machine and the associated core thermal response. The neutronic worth of the radial reflectors is approximately $\$ 40$ which requires the platen displacement to be controlled very precisely during the approach to critical and excess reactivity insertion. The boron carbide control rod that would be used in a flight system, with stationary reflectors, is only worth around $\$ 8$ so the rod displacement mechanism would have to travel several times further to start the reactor and provide the total excess reactivity associated with the core temperature setpoint. From time $T_{0}+0.40$ to $T_{0}+1.48$ hours, additional reactivity was inserted by 


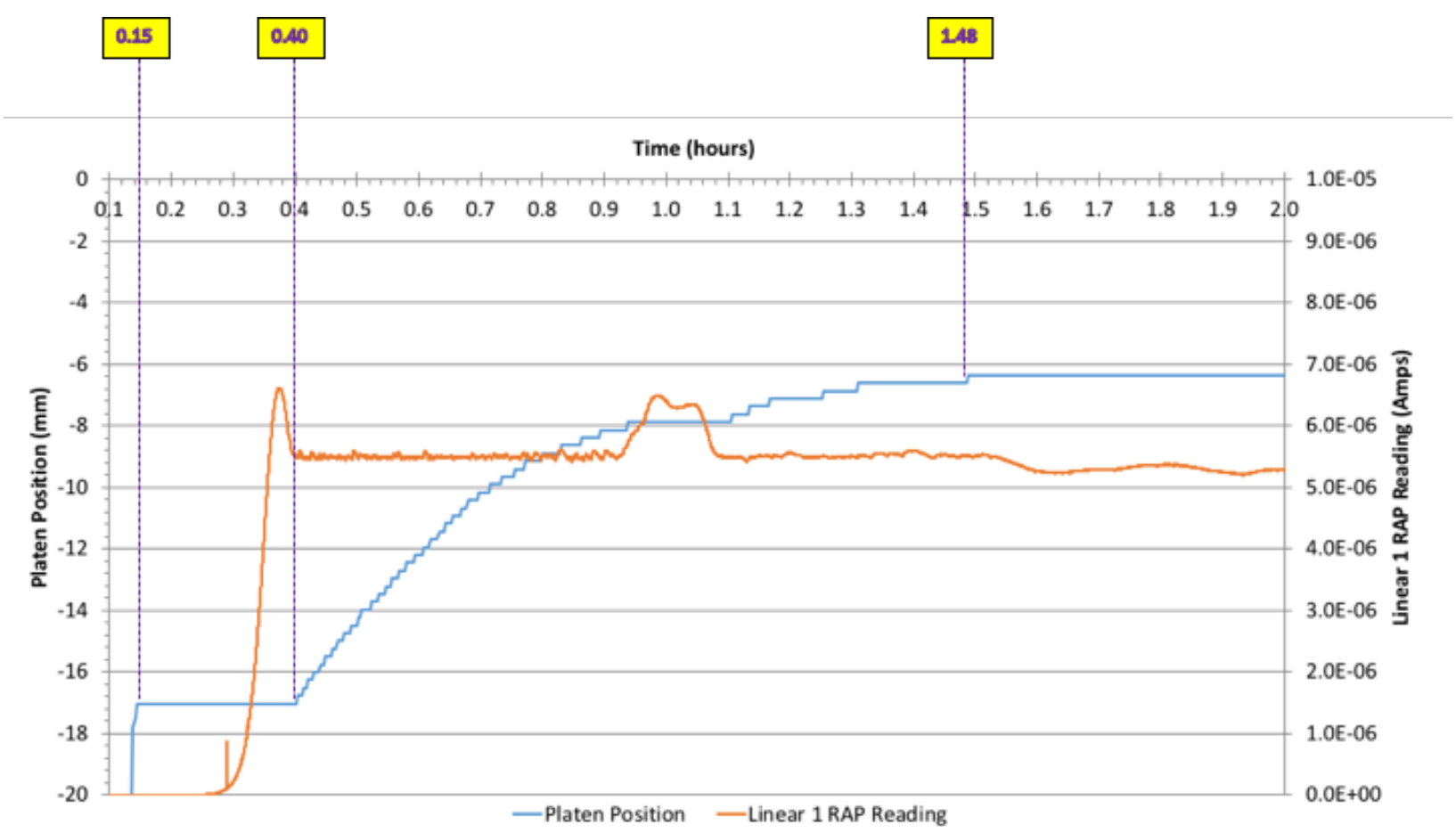

Fig. 7 Neutron detector reading and platen position during reactor startup

incrementally moving the platen and radial reflectors toward closure to compensate for the loss in reactivity from the thermal expansion of the core. The platen was held at $-6.35 \mathrm{~mm}$ for 5.0 hours while the system approached steady state.

The average temperatures and core neutron count during reactor startup are plotted against time in figure 8 . At $T_{0}$ +0.26 the reactor is critical and producing measurable thermal power as the core begins to heat. At $T_{0}+0.4$ the $\$ 0.15$ freerun has past its power peak and the Comet operator begins to insert more reactivity by moving the platen up in slow increments to keep the core power level at around $3 \mathrm{~kW}_{\mathrm{t}}$. The core heats up fairly rapidly at $30^{\circ} \mathrm{C} / \mathrm{min}$ until the heat pipes start to carry heat away from the core and towards the power conversion system at $T_{0}+0.58$ hours. The sodium vapor transports the thermal energy up the adiabatic section of the heat pipe until it reaches the condenser section at approximately 0.7 hours and begins to heat up the condenser, Stirling engines, and simulators. At $T_{0}+0.93$ hours the heat pipes reached a temperature that allowed greater thermal transport and cooled the core at a faster rate. This increased cooling rate created the boost in the core's thermal power as can be seen with the hump shaped curve. At 1.13 hours the Stirling engine hot ends reached a temperature of $650^{\circ} \mathrm{C}$ and were started. The thermal draw can be seen as the hot ends cool due to the heat absorption from the engine. The simulators were also turned on at this time with the cooling gas flow rate increasing up until their final setpoint was reached at 1.28 hours.

The reactor startup took approximately 1.5 hours to reach $800^{\circ} \mathrm{C}$ which is fairly quick compared to expected flight requirements. There is no known need for a fast startup of the reactor during flight so it is likely that the KRUSTY test provided a successful benchmark for a worst case startup scenario. The $\$ 0.15$ insertion is also not a likely startup scenario but was used during the testing to provide valuable data for neutronic code benchmarking. During flight, it is expected that the control rod would be removed at a very slow rate that would heat up the core at approximately $10^{\circ} \mathrm{C} / \mathrm{min}$. By using heat pipes, the reactor coolant and waste heat rejection does not require the use of pumps and electrical energy. The reactor will require very little energy storage to power the control rod motor and Stirling controller startup sequence, ultimately saving mass and complexity.

\section{Reactor Load Following During Extreme Conditions}

At 6.50 hours the platen was lowered $0.76 \mathrm{~mm}$ to decrease the core temperature from $830^{\circ} \mathrm{C}$ to $800^{\circ} \mathrm{C}$. This adjustment was the only correction needed to set the temperature and was a good measure of the accuracy of the neutronic model. It is expected that this type of small adjustment will be necessary during the startup stage of a mission. For a long duration mission, the control rod could be left alone after startup for the remainder of the mission with a 
temperature degradation of approximately $10^{\circ} \mathrm{C} / \mathrm{year}(1 \mathrm{kWe}$ design) or be adjusted periodically to maintain the 800 ${ }^{\circ} \mathrm{C}$ setpoint with a built-in excess reactivity of approximately $\$ 0.02 /$ year.

As the testing continued at the 8.00 hour mark, the Stirling engines and simulators were turned down to verify the reactor would load follow a power reduction scenario. This would be an expected mission scenario as the spacecraft or lander would have a reduction in power demand during certain parts of the mission. It is advantageous for the flight controller to turn down the Stirling engines and draw less thermal power from the reactor during these times to reduce the overall fluence of the reactor and thus minimize radiation doses to the hardware. The reactor handled the transient with ease and continued to operate at $800^{\circ} \mathrm{C}$. Hours 9.00 through 10.00 brought the system back to nominal operating conditions. At 10.04 hours the first maximum cooling load was started to test how the reactor would respond to a

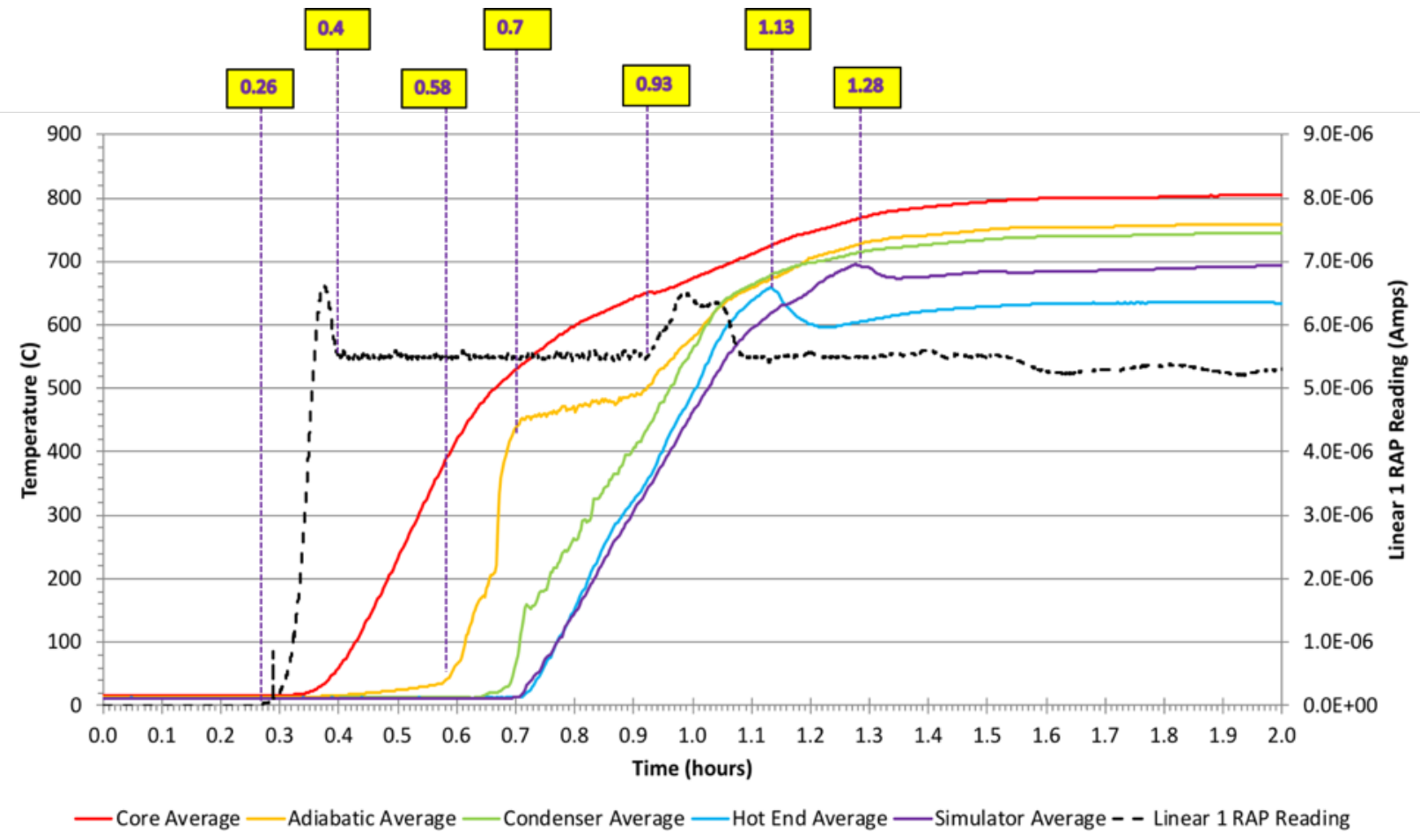

Fig. 8 Average system temperatures and neutron count during reactor startup

scenario where the spacecraft demanded maximum electrical power output from the system. Figure 9 graphically represents the responses of the average core temperature and neutron count/thermal power of the reactor during each transient. The core drops from $800^{\circ} \mathrm{C}$ to $792^{\circ} \mathrm{C}$ during the first oscillation of the maximum cooling load and quickly settles out in one hour. It can also be seen that the period of oscillation decreases as the power levels increase. This makes sense knowing that the faster the core cools, the faster the fuel will shrink and respond with an increased power output. All this happens through the passive physics associated with the negative temperature feedback of the fuel. No control rod movement is necessary.

Figure 10 illustrates an opposite scenario that was conducted at 27.04 hours where the entire power conversion system is shut off and the reactor has essentially lost all of its cooling capacity other than thermal losses. This is an off-nominal scenario that simulates a total shutdown of the power conversion system representing the worst case reactor cooling loss. Even so, the reactor quickly responds with a slight overshoot of $14^{\circ} \mathrm{C}$ which dampens out in approximately one hour after the step change. It is believed that these two scenarios represent the maximum and minimum cooling transients that the reactor would incur in mission operations and therefore bound all nominal and off-nominal events. This data provides compelling evidence that the reactor stability is sound and that future ground testing of such scenarios are not necessary for this system. 


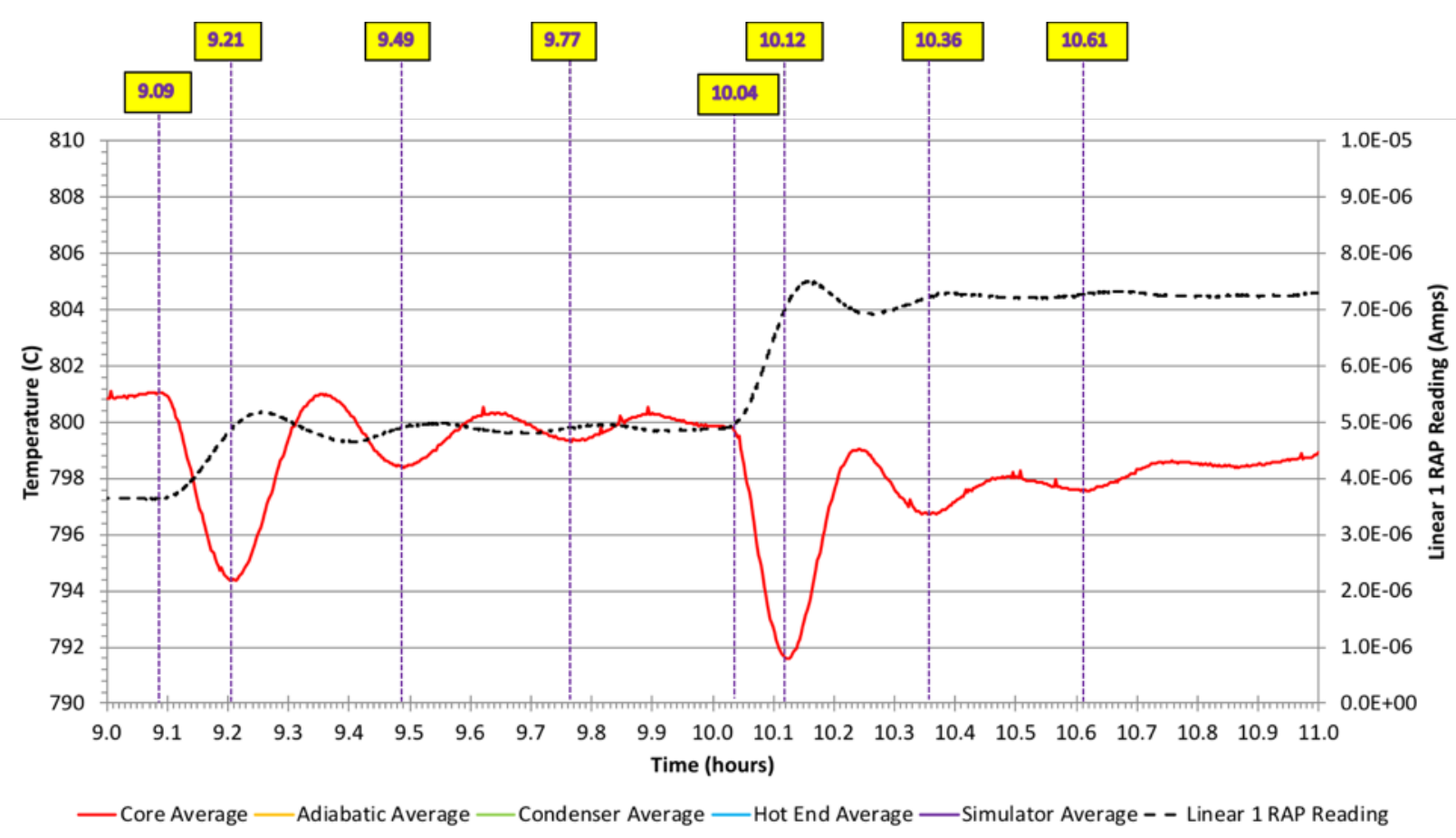

Fig. 9 Maximum thermal power draw from power conversion system simulating maximum electrical power demand from spacecraft

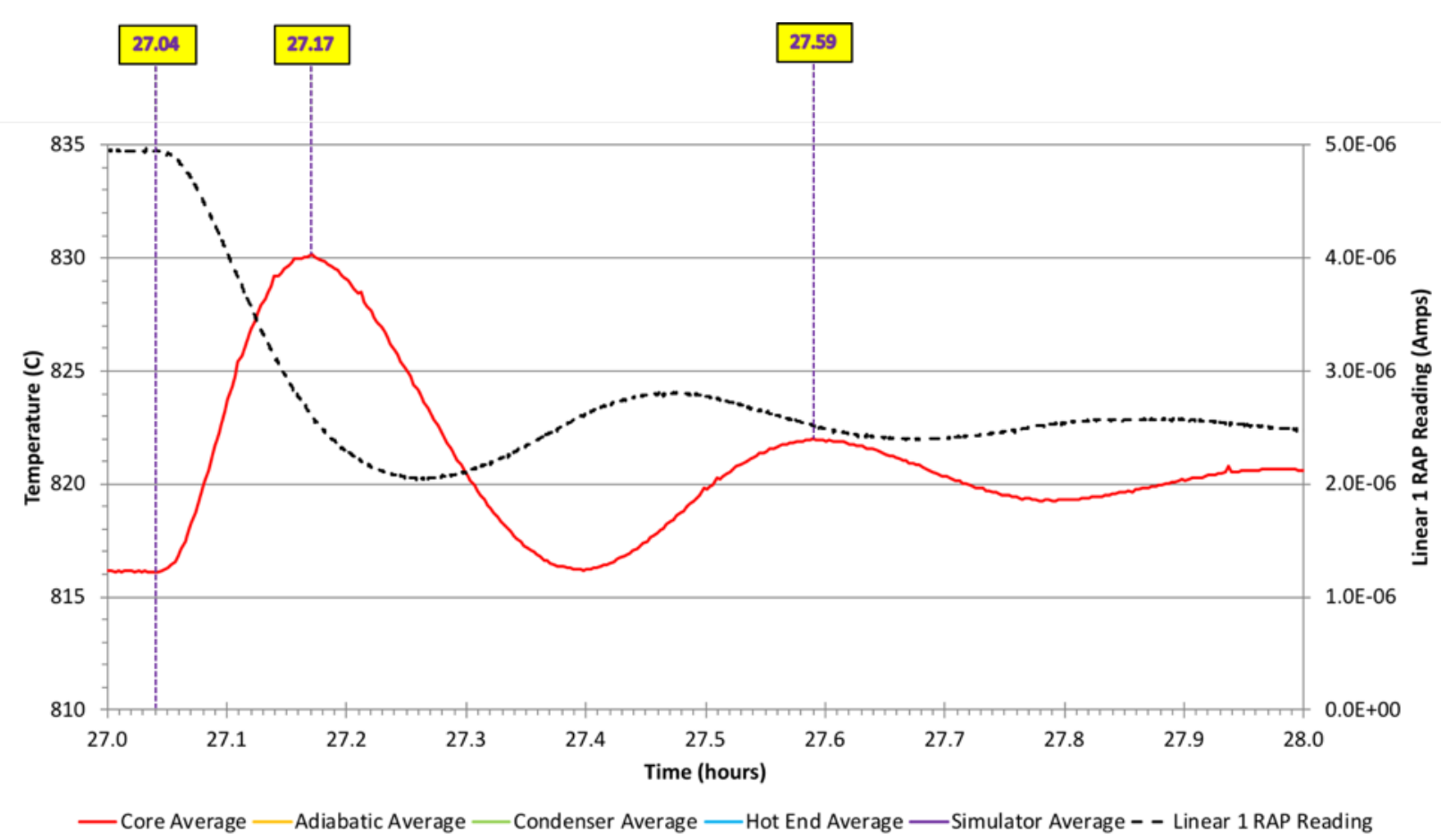

Fig. 10 Power conversion system shutdown simulating worst case mission scenario of reactor cooling loss 


\section{Simulated Heat Pipe and Stirling Failure}

Another off-nominal failure scenario that was simulated during the test can be observed in figure 11 . This set of sequences started with the 0 degrees location Stirling simulator being shut off at 12.02 hours followed by a second shutoff of the 180 degrees simulator at 13.01 hours. In this multiple failed Stirling engine or heat pipe scenario, the response from the flight controller would likely be to turn up the remaining Stirling engines to compensate for the drop in electrical power. This response was executed during the testing at 12.48 hours with the remaining Stirling simulators being ramped up accordingly to pull more thermal energy from the core at the remaining locations. This in turn creates an asymmetric temperature profile within the core which can be observed in the graph. Thermocouples attached to the core at the 22.5 and 337.5 degree locations rise in temperature as the 0 degree heat pipe and simulator stop moving heat away from the core. Likewise, as the 180 degree simulator is shut down the 157.5 and 202.5 degree core locations rise in temperature as expected. Once more, the remaining operating Stirling simulators are ramped up to provide the required thermal power draw at 13.53 hours to meet the anticipated spacecraft electrical output. In order to do this during a mission, the flight engines would need to be oversized to account for such failure modes and provide the necessary redundancy for continued output of the required power. Similarly, the heat pipes would be required to carry the additional thermal energy during such failure scenarios. This data in particular was extremely useful for modeling the asymmetric behavior of the core and provided confidence that the system could handle multiple failures and continue to meet power demands. Ultimately, the flight design will have to take into account the overall system redundancy and failure risk based on specific mission requirements before determining the final engine size and power levels. For example, an array of $250 \mathrm{~W}_{\mathrm{e}}$ engines could produce a maximum power level of $2 \mathrm{~kW}_{\mathrm{e}}$ but still be able to produce the required $1 \mathrm{~kW}_{\mathrm{e}}$ if half of the engines or heat pipes failed. Because the reactor is a constant temperature device, the core will produce whatever thermal power is required to keep the core at the temperature setpoint. So, the exact same core used in the KRUSTY test will produce $8 \mathrm{~kW}_{\mathrm{t}}$ at $800^{\circ} \mathrm{C}$ to power an array of $8250 \mathrm{~W}$ engines operating at full power. Therefore, the best operating power level of the reactor is related to the optimum balance between the system thermal resistance and Stirling hot end temperature for maximum electrical output.

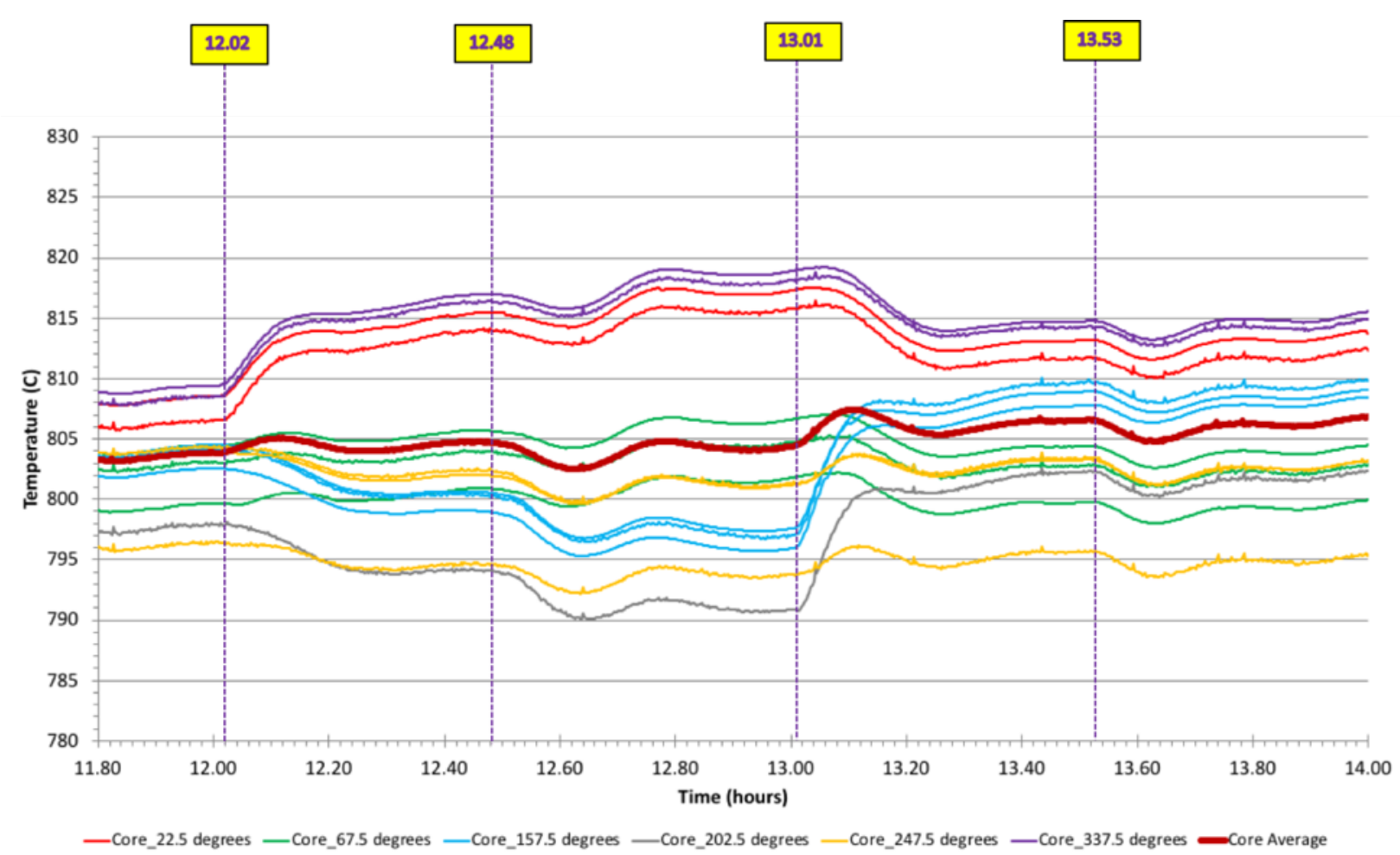

Fig. 11 Simulated failure of two Stirling engines or heat pipes at the 0 and 180 degree core locations at 12.02 and 13.01 hours respectively 


\section{E. Setting the Reactor Temperature}

Figure 12 illustrates the mission simulation of setting the reactor temperature by moving the control rod in a flight system. This is accomplished in the test by moving the platen and attached radial reflectors. The 16.00 and 17.00 hour operations show the effects of moving the platen down approximately $0.5 \mathrm{~mm}$ and the accompanying drop in core temperature of 30 degrees each time. At 17.98 hours the platen position was moved up a total of $1.52 \mathrm{~mm}$ for a temperature of $840^{\circ} \mathrm{C}$. As expected, the reactor physics quickly controlled the core to a steady temperature at the new setting. If desired, moving the control rod throughout a mission is easy to do and could allow the spacecraft to adjust the temperature over time, shut off the reactor completely, or any point in between. For example, the core could be used as a low temperature heat source during long transits to keep the system on warm standby without starting the heat pipes or power conversion systems.

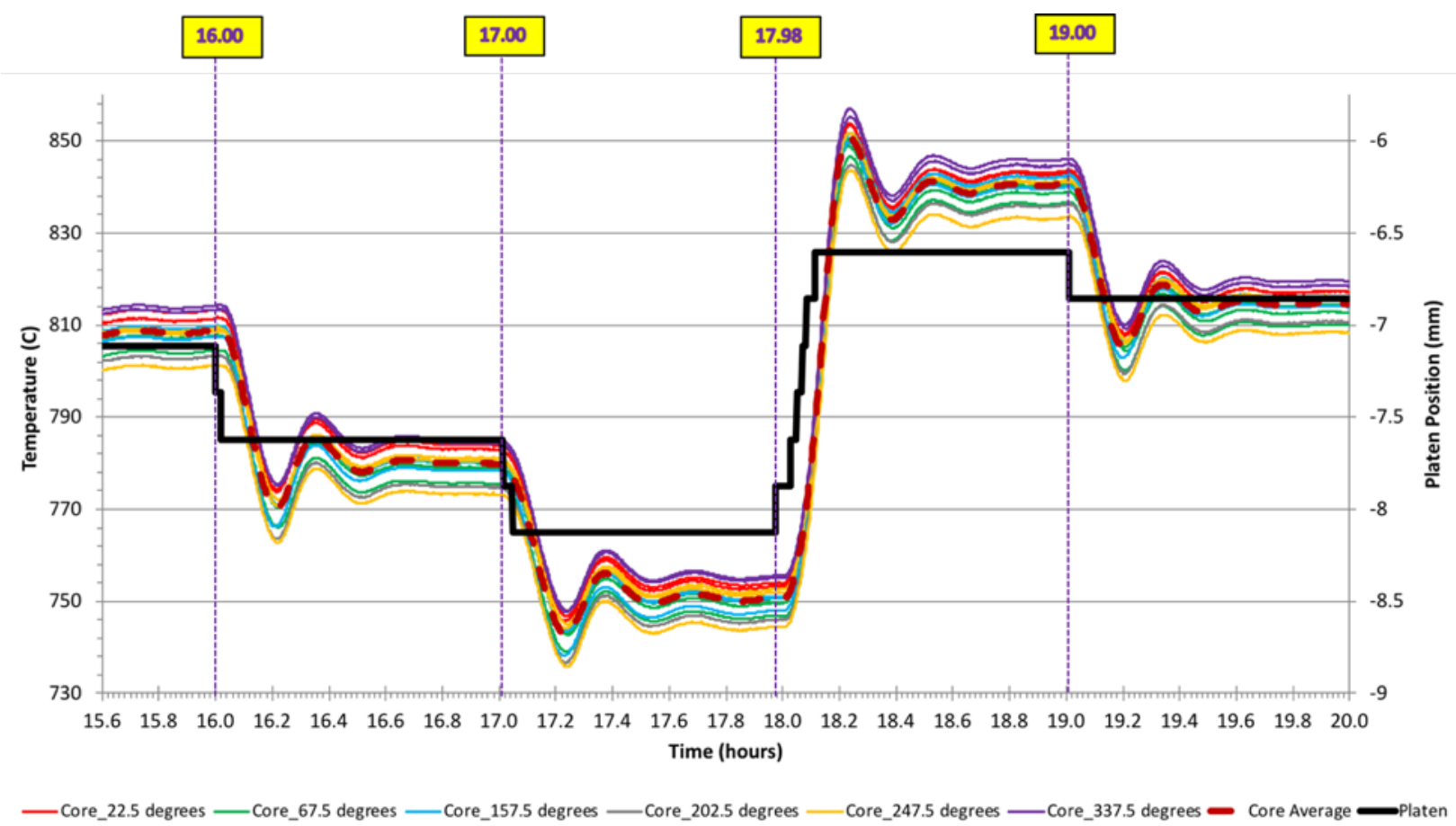

Fig. 12 Setting the reactor temperature using the radial reflector/platen position. This simulates setting the temperature of a flight system using the control rod position.

\section{F. Stirling Engine Operation}

The KRUSTY experiment could have been performed entirely with the Stirling thermal simulators knowing that the thermal sinks and sources of the system control the reactor dynamics. The conversion of thermal energy to electrical energy using Stirling engines is very well understood using electrical heat sources but coupling the engines to a nuclear heat source provided a new opportunity to learn. Figure 13 shows the hot and cold end temperatures of the two $80 \mathrm{~W}$ class Stirling engines and their associated electrical power output and thermal efficiency. The engines were mounted directly to a heat pipe and independently operated using a dedicated controller that synced the engine and its balancer to reduce the inertial vibrations. The data indicates that engine 1 operated at a maximum sustained power level of $95 \mathrm{~W}_{\mathrm{e}}$ with engine 2 trailing at $88 \mathrm{~W}_{\mathrm{e}}$ for a combined steady state maximum of $183 \mathrm{~W}_{\mathrm{e}}$. The engine thermal efficiency ranged from 30-34\% at approximately 50\% of Carnot depending on setpoints and transient thermal inputs. The system needed to be at steady state for long periods of time before the gas calorimetry and thermal efficiency numbers were useful.

Specific to Stirling dynamic power conversion and fission power systems is the ability to vary the power level and range using either piston amplitude or reactor control rod adjustments. The Sunpower design used for the KRUSTY 


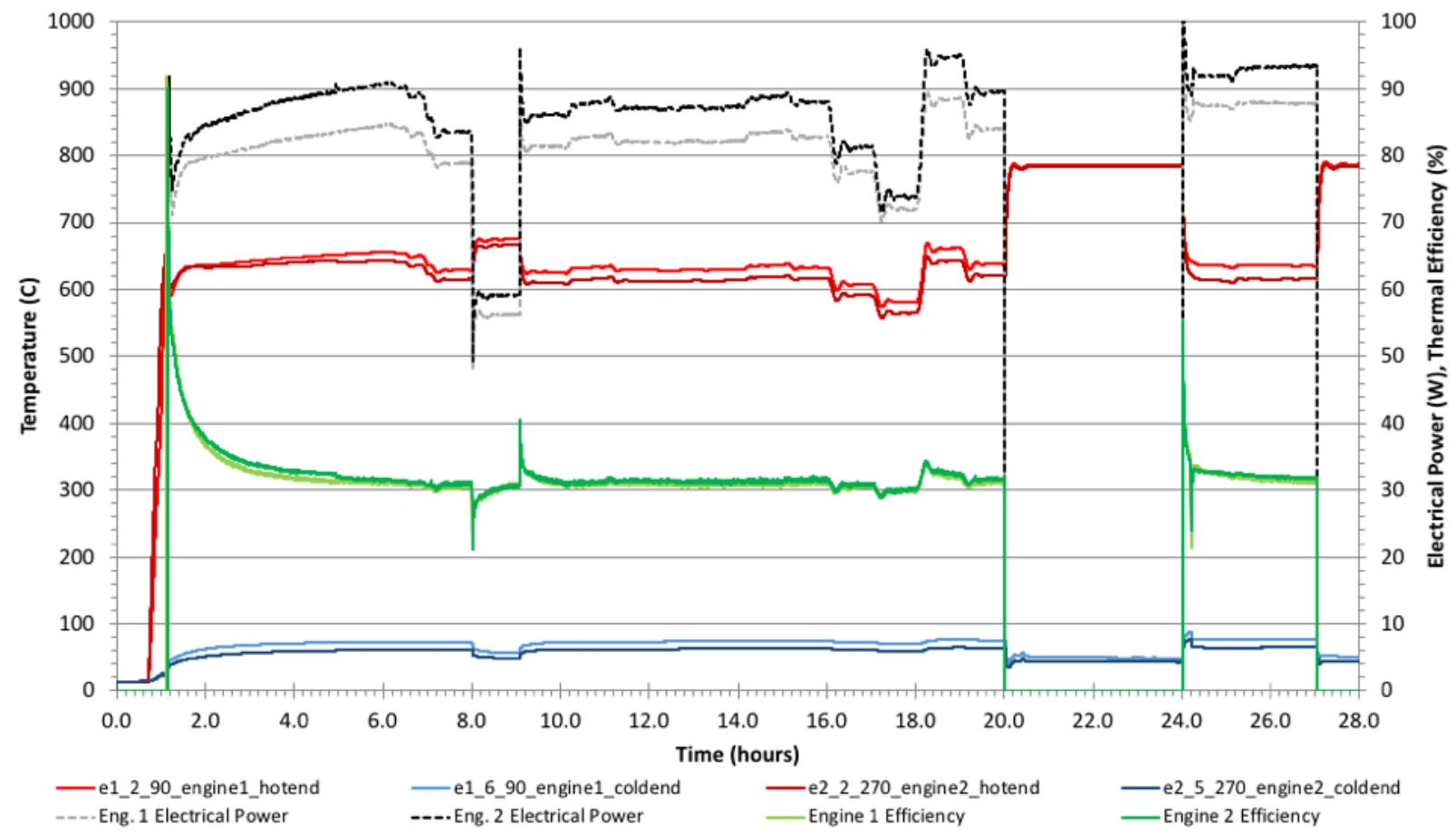

Fig. 13 Stirling convertor performance showing electrical power output, hot and cold end temperatures, and thermal efficiency

test would allow each engine to be turned down to around $50 \%$ of its electrical power output before approaching the gas bearing operating limits. During a mission, it is realistic that several engines could be shut off while leaving one running at 50\% power allowing the Kilopower system to operate at a power turn down ratio of 16:1 assuming a total of 8 engines. Alternatively, the reactor control rod could be adjusted to provide a lower Stirling hot end temperature and electrical output for an even greater turn down ratio. This level of power range and control provides new capabilities that could potentially enhance future mission operations.

\section{G. Conclusions and Lessons Learned}

All three technical objectives were successfully met during the KRUSTY experiment. The reactor operated at steady state with a thermal power output of over $4 \mathrm{~kW}_{\mathrm{t}}$ at a temperature of $800^{\circ} \mathrm{C}$, the reactor precisely controlled the core temperature through several simulated nominal and off-nominal mission scenarios, and the data is being used to benchmark the nuclear codes and material cross sections needed for the next design iteration. The reactor nuclear and mechanical systems have achieved a Technology Readiness Level (TRL) of 5 having successfully demonstrated the reactor technology in a relevant environment.

The KRUSTY nuclear ground test is the first space reactor test completed in over 50 years and many technical and programmatic lessons were learned during the process. NASA has completed several electrically heated power conversion tests related to fission power systems over the years but had struggled to define and execute a nuclear test. There were several key factors in the success of the KRUSTY experiment that will hopefully help future projects be successful.

The first lesson learned is to define and execute clear project objectives in less than 3 years. The technology investors want to see quick technical progress so having a detailed plan that has clear milestones at short intervals is advantageous. Hitting the milestones increases the investors' confidence in the team's ability to complete the project and successfully develop the technology. Ultimately, the KRUSTY experiment took 3-1/2 years to complete from concept to test.

The second lesson learned is making it affordable. There are several ways to make things affordable but most revolve around creativity. For KRUSTY, the team's creativity defined an existing fuel that was in production and available at the Y12 national security complex. The cast metal fuel used in KRUSTY cannot be operated as hot as some of the oxide fuels but it was available and could be cast and machined into custom shapes that allowed freedom 
of design over pin type oxide fuels. Making the decision to test the smaller Kilopower reactor allowed the testing to be done inside DAF using existing facilities. This was a major cost savings as building or modifying nuclear facilities takes a lot of time and money which would have violated the 3 year and affordable rules. The larger Kilopower reactor would have been too large for running the test inside the DAF and would have cost much more money to do at one of the underground facilities. Using existing Stirling engines and building thermal simulators also saved the project money and schedule in comparison to developing eight optimized engines.

The third lesson also compliments affordability but focuses more on timeliness of decisions and execution. This is done by keeping the team small by recruiting multidisciplinary and energetic engineers that can both complete a wide range of tasks personally and effectively manage the completion of many other tasks. The term small is relative for every project depending on system size and complexity but the understanding should be clear. For example, the design of the flight specific KRUSTY power system was completed in 6 months and 3000 engineering hours. Prototype fabrication, assembly, and testing took much longer but was mostly completed by the same core group of engineers allowing a short time period between test results and design revisions. The ability to quickly design, build, and test systems and components provided valuable experience and test data that made the KRUSTY experiment so successful.

\section{References}

[1] D. I. POSTON, et. al.,"Design of the KRUSTY Reactor”, Proceedings NETS-2018, ANS (2018).

[2] Palac, Don T, et al., "Kilopower KRUSTY Fission Power Demonstration Update," Proceedings NETS-2018, ANS (2018).

[3] Gibson, Marc A., Oleson, Steve R., Poston, David I., and McClure, Patrick R. "NASA's Kilopower Reactor Development and the Path to Higher Power Missions.” IEEE Aerospace Conf. Big Sky, MT: paper 2457, 2017

[4] Gibson, Marc A., Max Briggs et al. "Heat Powered Stirling Conversion for the Demonstration Using Flattop Fission (DUFF) Test." Nuclear and Emerging Technologies for Space. Albuquerque: NETS paper 6812, 2013.

[5] Poston, David I., and Patrick R. McClure. "The DUFF Experiment-What was Learned." Nuclear and Emerging Technologies for Space. Albuquerque: NETS paper 6967, 2013. 